\title{
Effectiveness of shunting in patients with normal pressure hydrocephalus predicted by temporary, controlled-resistance, continuous lumbar drainage: a pilot study
}

\author{
I H Chen, C I Huang, H C Liu, K K Chen
}

\begin{abstract}
From 1984 to 199215 consecutive cases of normal pressure hydrocephalus were included in this pilot study. A series of tests included CT of the brain, grading of the cognitive mental state with the minimental state examination; urodynamic studies, and gait evaluation. These tests were carried out on admission, and repeated on day 1 , day 3 , and day 5 after controlled-resistance, continuous lumbar drainage (CRCLD). During this period, eight patients showed significant improvements of cognitive mental state, urodynamic studies, or gait and were regarded as CRCLD responders; the remaining seven patients were regarded as CRCLD non-responders. The CRCLD was routinely removed on day 6 after the drainage procedure and a ventriculoperitoneal (VP) or a lumboperitoneal (LP) shunt was randomly selected for each patient. The tests were repeated one week after shunting and a year later.

All the CRCLD responders continued to benefit from shunting at one week and one year after the procedure irrespective of the type of shunting they received. By comparison, none of the CRCLD nonresponders showed any improvement a year after the shunting.

In conclusion, CRCLD proved to be a safe and effective way to predict the effectiveness of shunting in patients with normal pressure hydrocephalus.
\end{abstract}

$(\mathcal{F}$ Neurol Neurosurg Psychiatry 1994;57:1430-1432)

Neurological Institute C I Huang

H C Liu

Department of

Urology, Veterans

General Hospital,

Taipei, Taiwan,

Republic of China

K K Chen

Correspondence to:

Dr Ih-Hsin Chen,

Department of

Neurosurgery, Taipei

Municipal Chung-Hsiao

Hospital, 87 Tung-Teh

Road, Nankang, Taipei,

Taiwan, Republic of China.

Received 22 September 1993

and in final revised form

31 January 1994

Accepted 27 May 1994
Materials and methods

PATIENT SELECTION

From 1984 to 1992,15 consecutive cases admitted with possible normal pressure hydrocephalus were included in this pilot study with dementia and gait disturbance with or without urinary problems; enlarged ventricles seen on CT; and no evidence of cortical atrophy on CT.

\section{CLINICAL ASSESSMENT}

All the patients were submitted to a series of tests that comprised (1) CT of the brain; (2) grading of cognitive mental state by a neurologist (UCL) with a Chinese version of the mini mental state examination (MMSE), ${ }^{2}$ which includes items that assess orientation, registration, recall, attention, calculation, language, and visual constructional tests. Clinical improvement or deterioration was defined as significant if there was an increment or decrement of more than five points on the MMSE score (scoring from 1-30) in a series of examinations; (3) urodynamic studies, which included cystometry, sphincter electromyography, urethral pressure profile, and uroflowmetry. Clinical improvement was defined as significant if at least one of these tests, when previously abnormal, showed functional restoration; (4) gait disturbance: improvement was defined as significant when a bedridden patient could walk after CRCLD or shunting, or the number of steps needed to advance 18 metres decreased by at least $50 \%$.

These evaluations were made on admission, and repeated one day, three days, and five days after CRCLD. During this period, if any improvements in mental state, urodynamics, or gait were recorded when compared with the baseline data on admission then these patients were regarded as CRCLD responders. Conversely, those with no improvement were regarded as CRCLD responders. We routinely removed CRCLD on the sixth day after the drainage procedure. Shunting of CSF was performed for every patient included in this study; by random selection seven of these patients received a ventriculoperitoneal shunt and eight received a lumboperitoneal shunt. The opening pressure for these shunts was determined by the medium pressure distal valves on the 
peritoneal catheters (Codman and Shurtleff Inc, Randolph, MA, USA). Evaluations were made again one week after CSF shunting and a year later by a neurologist who was blind to the results of CRCLD.

TECHNIQUE FOR CONTROLLED-RESISTANCE, CONTINUOUS LUMBAR DRAINAGE

After informed consent of patients and their relatives, CRCLD were performed under strictly aseptic techniques. A silicon catheter $(0.032 \times 0.052$ inches outside diameter, SilMed corporation, MA, USA) was introduced through a 14 gauge Touhy needle into the lumbar subarachnoid space at the L4-L5 (occasionally at the L3-L4) interspace and directed $10 \mathrm{~cm}$ cephalad in the subarachnoid space. The Touhy needle was then withdrawn. The proximal end of the catheter was connected to a sterile closed collection system that consisted of an ordinary intravenous infusion set with a volume control bag (Miles Canada Inc Saftiset $183 \mathrm{~cm}$ with $100 \mathrm{ml}$ Volu-Trole vented IV set) attached to the flank with a long free segment by a sterile adhesive tape (3M Inc, Tegaderm 1626). These patients were allowed to ambulate freely with their collection bags at the same level as the entry of the catheter. The CSF drainage rate was adjusted to about $15-18 \mathrm{ml}$ per hour by a roller clamp according to the amount of CSF drained over the previous hour. The dressing, if wet, was changed with an aseptic technique. No prophylactic antibiotics were given.

\section{Results}

The table shows the clinical features and outcome of these 15 patients after CRCLD and shunting. We routinely repeated the CT of the brain five days after CRCLD and compared the ventricular size before and after CRCLD. It showed a decrease in all 15 patients. Improvements in dementia, gait disturbance, or urinary incontinence were noted in eight patients. All eight patients grouped as CRCLD responders continued to benefit

Clinical manifestation and results of CRCLD and definite shunting in 15 patients with normal pressure hydrocephalus

\begin{tabular}{|c|c|c|c|c|c|c|c|c|}
\hline \multirow[b]{3}{*}{ Patient } & \multirow[b]{3}{*}{$\operatorname{Sex}$} & \multirow[b]{3}{*}{ Age } & \multirow[b]{3}{*}{ Aetiology } & \multicolumn{3}{|c|}{ Normal pressure hydrocephalus triads } & \multirow{3}{*}{$\begin{array}{l}\begin{array}{l}\text { One year } \\
\text { after } \\
\text { shunt }\end{array} \\
D G B\end{array}$} & \multirow[b]{3}{*}{ Shunt } \\
\hline & & & & \multirow{2}{*}{$\frac{\text { Admission }}{D G B}$} & $\begin{array}{l}\text { Five days } \\
\text { after } \\
C R C L D\end{array}$ & $\begin{array}{l}\text { One week } \\
\text { after } \\
\text { shunt }\end{array}$ & & \\
\hline & & & & & $D G B$ & $D G B$ & & \\
\hline 1 & M & 65 & CVA & +++ & I U U & I I U & I I U & LP \\
\hline 2 & $\mathrm{~F}$ & 54 & Trauma & +++ & $U U U$ & U U U & U U U & LP \\
\hline 3 & M & 77 & Unknown & +++ & UUU & U U U & U U U & $\mathrm{VP}$ \\
\hline 4 & $\mathrm{~F}$ & 73 & Unknown & +++ & U I U & I I U & I I I & LP \\
\hline 5 & $\mathbf{M}$ & 48 & Trauma & +++ & U U I & I U I & I I I I & $\overline{\mathrm{LP}}$ \\
\hline 6 & M & 72 & Unknown & ++- & I I - & I I - & I I - & LP \\
\hline 7 & $\mathbf{M}$ & 77 & Unknown & ++- & I I - & I I - & I I - & VP \\
\hline 8 & M & 69 & Trauma & +++ & I I I I & I I I & I I I & LP \\
\hline 9 & M & 66 & Unknown & +++ & UU U & $\cup \cup U$ & $\mathbf{U} \mathbf{U}$ & VP \\
\hline 10 & $\mathbf{M}$ & 78 & CVA & +++ & U U U & U U U & $\mathbf{U} \mathbf{U} \mathbf{U}$ & VP \\
\hline 11 & M & 47 & Trauma & +++ & U U U & UUU & $\mathbf{U U U}$ & VP \\
\hline 12 & $\mathbf{M}$ & 64 & Trauma & +++ & I U U & I U U & I U U & LP \\
\hline 13 & M & 69 & Unknown & +++ & I I I I & I I I & I I I & VP \\
\hline 14 & $\mathrm{~F}$ & 67 & Unknown & +++ & $\mathbf{U} \mathbf{U}$ & $\mathcal{U} \mathbf{U}$ & $\mathbf{U} \mathbf{U}$ & LP \\
\hline 15 & $\mathbf{M}$ & 63 & CVA & +++ & $\mathrm{UUU}$ & $\mathbf{U U U}$ & $\mathbf{U} \mathbf{U} \mathbf{U}$ & VP \\
\hline
\end{tabular}

$\mathrm{D}=$ Dementia; $\mathrm{G}=$ gait disturbance; $\mathrm{B}=$ bladder dysfunction; $\mathrm{U}=$ Unimproved; $\mathrm{I}=$ improved; + = symptom presented; - = symptom not present; VP = ventriculoperitoneal; $\mathrm{LP}=$ lumboperitoneal. from CSF shunting whereas none of the remaining seven grouped as CRCLD nonresponders showed any improvement either a week or a year later. No complications from the CSF drainage procedure were noted among these patients.

\section{Discussion}

Shunting of CSF for patients with clinical features suggestive of normal pressure hydrocephalus remains a neurosurgical dilemma. It may be optimistic to expect clinical improvement in patients whose initial symptoms are mental impairment or urinary incontinence and the complication rate among these elderly patients is over $25 \%$ in many series. ${ }^{34}$ When the history shows that the gait disturbance precedes impaired mentation or becomes overt at the same time, there is a good chance of recovery after CSF shunting whereas in those patients in whom dementia comes first or is not associated with a gait disturbance, the chance of improvement is low. ${ }^{5}$ Only half of the patients with the classical picture of ventricular reflex and convexity block in isotope cisternography and patients without the typical picture may benefit from treatment. $^{36}$

Repeated CSF tapping or continuous lumbar drainage have been suggested to be of predictive value. ${ }^{78}$ To avoid complications related to excessive CSF drainage, we have used a controlled drainage system. In this study, every CRCLD responder proved to be a CSF shunting responder both at one week and one year after the procedure irrespective of the type of shunt. By contrast, none of the CRCLD non-responders showed any benefit at all over the same period. The results imply that the effectiveness of CSF shunting in patients with normal pressure hydrocephalus can be predicted by temporary CRCLD.

Although some authors have advocated absolute bed rest during continuous lumbar drainage, ${ }^{48}$ we do not believe that it is necessary with our system because the drainage rate of our collecting system can be effectively regulated by a roller clamp rather than by the pressure gradients. Early ambulation with the collecting system did not alter the drainage rate very much, and complications related to a prolonged immobilisation such as deep vein thrombosis are avoided. Caution should be taken to regulate the drainage rate periodically by adjusting the roller clamp. We have experienced one among 48 patients who received CRCLD for a CSF fistula and developed an acute subdural haematoma and pneumocephalus six days after CRCLD. ${ }^{9}$ In retrospect, this complication was caused by the over drainage of CSF due to loosening of the roller clamp. This complication may be effectively prevented by careful nursing with attentive adjustment of the drainage rate.

In conclusion, this preliminary study suggests that CRCLD provides a safe and effective way to predict the outcome of shunting among patients with possible normal pressure hydrocephalus. 
1 Hakim S, Adams AD. The special problem of symptomatic hydrocephalus with normal cerebrospinal fluid pressure. Observation on cerebrospinal fluid hydrodynamics. I Neurol Sci 1965;2:307-27.

2 Folstein MF, Folstein SE, McHugh PR. "Mini-mental state". A practical method for grading the cognitive state of patients for the clinician $₹$ Psychiatr Res 1975 ; 12:189-98.

3 Black PM. Idiopathic normal pressure hydrocephalus. Results of shunting in 62 patients. $\mathcal{F}$ Neurosurg $1980 ; 52$ : R71-7.

Hughes CP, Siegel BA, Coxe WS, et al. Adult idiopathic communicating hydrocephalus with and without shunting. F Neurol Neurosurg Psychiatry 1978;41:961-71.

5 Fisher CM. The clinical picture in occult hydrocephalus.
Clin Neurosurg 1977;24:270-84.

6 Laws ER Jr, Mokri B. Occult hydrocephalus: results of shunting correlated with diagnostic tests. Clin Neurosurg 1977;24:316-33.

7 Ahlberg J, Norlen L, Blomstrand C, et al. Outcome of shunt operation on urinary incontinence in normal pressure hydrocephalus predicted by lumbar puncture. $\Im$ Neurol Neurosurg Psychiatry 1988;51:105-8.

8 Haan J, Thomeer RTWM. Predictive value of temporary external lumbar drainage in normal pressure hydroexternal lumbar drainage in normal
cephalus. Neurosurgery 1988;22:388-91.

9 Huang CI, Huang MC, Chen IH, et al. Diverse applications of continuous lumbar drainage of cerebrospinal fluid in neurosurgical patients. Ann Acad Med Singapore 1993;22 (suppl):456-8. 